\title{
Prevalence of acute malnutrition among children ages 6-59 months: Results from a baseline nutrition survey in North-Western Uganda.
}

\author{
Ismail D. Legason ${ }^{1,2^{*}}$, Ratib Dricile ${ }^{1,3}$ \\ ${ }^{1}$ Health and Development for All (HADA) Uganda Program, Kampala, Uganda \\ ${ }^{2}$ African Field Epidemiology Network, Kampala, Uganda \\ ${ }^{3}$ Texilla American University, Georgetown, Guyana
}

\begin{abstract}
Background: Acute malnutrition is particularly important in humanitarian emergencies where sudden change of food availability or high disease burden can cause this form of malnutrition. Alliance Forum for Development Uganda received funding from World Food Program to implement MCHN and TSFP in refugee settlement areas in Koboko district, North-western Uganda. As part of the program, a baseline nutrition survey was conducted to fast track the progress and contribution of the project towards improving the nutritional wellbeing of the refugees and host communities.

Methods: A cross-sectional study was carried out in the month of August in two sub counties in Koboko district. The selection of the sub counties and parishes therein was purposive, while 18 villages in selected parishes were randomly selected. The participants were invited to come to the nearest screening post for anthropometric measurements. Anthropometric data was analyzed using ENA software. While Stata version 12 was used to execute statistical tests for association. Statistical tests were two-sided.

Results: The prevalence of GAM was 5.6\% (4.2-7.4 95\% C.I.) and SAM was 1.1\% (3.2-5.8 95\% C.I.). GAM was higher among boys than in girls ( $7.7 \%$ vs. $3.9 \%)$. There were no statistically significant differences in prevalence of acute malnutrition by nationality (national: $8.7 \%$ vs. refugees: $6.2 \%, p=0.186$ ). Low child birth weight was statistically associated with acute malnutrition $(p=0.021)$. Severe acute malnutrition was more common among the age group 6-17 months $(1.2 \%)$ and decreased with age. The prevalence of oedema was $0.6 \%$.

Conclusion: By WHO thresholds, our results indicate that global acute malnutrition is a moderate situation in the refugee areas of Koboko district and that GAM affects both refugees and host communities. We recommend a repeat of the survey during a period of hunger gap to give a year-round nutrition situation in Koboko district.
\end{abstract}

Keywords: Acute malnutrition, Under-5, Refugees, Host communities, Northwestern Uganda.

Abbreviations: AFOD: Alliance Forum for Development; WFP: World Food Program; HADA: Health and Development for All; MCHN: Maternal-and-Child Health and Nutrition; TSFP: Targeted Supplementary Feeding Program; GAM: Global Acute Malnutrition; MAM: Moderate Acute Malnutrition; SAM: Severe Acute Malnutrition; EPI: Expanded Program on Immunization; MCH: Maternal Child Health; iCCM: Integrated Community Case Management; W/H: Weight for Height; SD: Standard Deviation; C.I: Confidence Interval; UBOS: Uganda Bureau of Statistics; UDHS: Uganda Demographic Health Survey

Accepted on January $17^{\text {th }}, 2018$

\section{Introduction}

Globally, approximately 52 million (8\%) children under the age of five years in 2011 were wasted and more than $70 \%$ were from Sub-Saharan Africa and Asia [1]. In Uganda, the national prevalence of acute malnutrition (wasting) among children 6-59 months of age is $4 \%$ and it is $10 \%$ for West Nile sub- region [2]. In South Sudan where most of the refugees in Uganda originate from, there is critical food shortage and famine is looming with prevalence of acute malnutrition in some areas estimated at $26.1 \%$ [3]. Malnutrition continues to be a serious public health concern especially in conflict and post-conflict recovery situations. Children weakened by all forms of malnutrition often die from diseases which are both preventable and easy-to-treat, such as diarrhoea, pneumonia, and malaria [4]. It also reduces and compromises cognitive development and physical health of the children at early stages of growth, which has generation consequences if not corrected before child reaches 23 months of age of irreversible damage [4-6]. Socio-economically, child malnutrition impacts on cognitive function and contributes to poverty through impeding individual's ability to lead a productive live $[4,7]$.

Acute malnutrition is particularly important in humanitarian emergencies where sudden change of food availability or high disease burden can cause this form of malnutrition. The political crisis in neighbouring South Sudan has displaced thousands into the neighbouring countries causing enormous challenges 
to the hosting countries like Uganda, with significant civil, social, economic, health and political implications $[8,9]$. The refugee population in Uganda according to UNHCR sources has now reached 1,199,051 and most of them in dire need of humanitarian interventions [10,11]. Alliance Forum for Development (AFOD) Uganda received funding from World Food Program (WFP) to implement Maternal-and-Child Health and Nutrition (MCHN) and Targeted Supplementary Feeding Program (TSFP) in refugee settlement areas in Koboko district, North-Western Uganda. The program targeting both refugees and host communities, involves children 6-59 months, pregnant and lactating women and women of reproductive age (15-49 yrs) who experience nutritional stress due to high physiological demand. To fast track the progress and contribution of the program towards improving the nutritional wellbeing of the refugees and host communities, a baseline nutrition survey was carried out in the refugee settlement areas and the neighbouring host communities. We report the results of acute malnutrition in children 6-59 months of age.

\section{Methods}

\section{Study setting}

The survey was conducted in two sub counties (Lobule and Kuluba sub-counties) in Koboko District. The population in the two sub counties is projected at 82,200 and the under-5 population estimated as 16,605 [12]. It is worth noting that the refugees in these settlements have been integrated into the local communities. As a result, they participate in most community programmes in the area, use the same resources as the local communities and are engaged in activities such as subsistence farming for livelihood. The climate in the area is semi-arid with bimodal rainfall pattern, the wettest periods being July-October and the driest being December-March. The period between March-July is described as the hunger gap in this region and the earliest crop harvests occur in August. The staple foods are cassava and beans. While crops like maize, peanuts, millet and sorghum are also grown. The communities here also keep animals such as chicken, goats, sheep and cattle but mainly for subsistence.

\section{Study design}

A cross sectional study was carried out in the month of August, a period that coincided with the first harvest season in the region. The survey was carried out in two sub counties in Koboko district where refugees have settled. The selection of the sub counties and the parishes therein was purposive, while villages in selected parishes were randomly selected. A total of 18 villages were selected. The village level population figures were obtained from the District Planning Unit and office of the Prime Minister in the case of refugees. A total of 13 screening posts were then established. Using a village household list, the participants were invited to come to the nearest screening post for anthropometric measurements. This was partly because of logistical challenges and inaccessibility of some of the villages and households. All the children ages 6-59 months in a selected village were screened.

\section{Inclusion/exclusion criteria}

All children ages 6-59 months in a selected village were eligible to participate upon consent by the parent or a responsible caretaker. Children were excluded if they were not accompanied by a responsible care taker.

\section{Data collection}

One-day training was organised to ensure that enumerators understood the objectives of the survey, data collection tools, anthropometric measurements, and importance of checking for errors at field level. Four teams were formed comprising of two enumerators and a supervisor. The supervisors (project staff) worked closely with the enumerators to ensure that enumerators took and recorded measurements correctly. Data was captured in Microsoft excel and then anthropometric data extracted into Emergency Nutrition Assessment (ENA) software version 2015. The data was reviewed, checked for plausibility and feedback given to the teams to proceed with data collection the following day. All survey equipment, for example weighing scales and height boards were calibrated or checked by the supervisors before they were handed over to the teams to be used for measurements. In any event of equipment becoming faulty during the field data collection, it was replaced by good one.

Anthropometric measurements included weight and height. Body weight was measured to the nearest $0.1 \mathrm{Kg}$ of a standing beam balance. It was measured with light clothing and no shoes. Calibration of the weighing scale was done before weighing each participant by setting it to zero. The weighing scale was also checked against a standard weight for its accuracy on daily basis. Height of the participants was measured using 'Seca' vertical height measuring scale with the subject standing upright in the middle of the board. The participants were asked to take off their shoes, stand erect and look straight in horizontal plain (Frankfurt plane). For infants who were unable to stand, a height board was used. The occiput, shoulder, buttocks, and heels touched the measuring board [13] and height was recorded to the nearest $0.5 \mathrm{~cm}$.

A questionnaire was used to collect information about sociodemographic factors, morbidity, vaccination against measles, and vitamin A supplementation in under-5s. Questions on child morbidity focussed on history of illness in the preceding two weeks of the interview and whether the child suffered from fever, cough, diarrhoea, and skin infections. Vaccination against measles was a particular concern given the association between malnutrition and measles. Parents were asked to come along with the child's $\mathrm{MCH}$ card and information such as immunization against measles, vitamin A supplementation and birth weight were extracted from the cards. Measles vaccination was asked among children 9 months and older; and for the refugees, the question was asked if a child was 6 months and older.

\section{Statistical analysis}

Emergency Nutrition Assessment software version 2015 was used to generate z-scores and the tables (Tables 1-4). Weight for Height Z-scores (WHZ) were generated using WHO 2005 Growth Standards. The WHO cut off points for global acute 
Table 1. Distribution of age and sex of sample.

\begin{tabular}{|c|c|c|c|c|c|c|c|}
\hline \multirow{2}{*}{ AGE (mo) } & \multicolumn{2}{|c|}{ Boys } & \multicolumn{2}{c|}{ Girls } & \multicolumn{2}{c|}{ Total } & Ratio \\
\cline { 2 - 8 } & no. & $\%$ & no. & $\%$ & no. & $\%$ & Boy: Girl \\
\hline $6-17$ & 135 & 50.2 & 134 & 49.8 & 269 & 27.5 & 1.0 \\
\hline $18-29$ & 95 & 45.5 & 114 & 54.5 & 209 & 21.4 & 0.8 \\
\hline $30-41$ & 95 & 41.9 & 132 & 58.1 & 227 & 23.2 & 0.7 \\
\hline $42-53$ & 93 & 44.7 & 115 & 55.3 & 208 & 21.3 & 0.8 \\
\hline $54-59$ & 22 & 33.8 & 43 & 66.2 & 65 & 6.6 & 0.5 \\
\hline Total & 440 & 45.0 & 538 & 55.0 & 978 & 100.0 & 0.8 \\
\hline
\end{tabular}

Table 2. Prevalence of acute malnutrition based on $\mathrm{W} / \mathrm{Hz}$-scores (and) or oedema) and by sex.

\begin{tabular}{|c|c|c|c|}
\hline Variables & $\begin{array}{c}\text { All } \\
n=928\end{array}$ & $\begin{array}{l}\text { Boys } \\
n=413\end{array}$ & $\underset{n=515}{\text { Girls }}$ \\
\hline $\begin{array}{l}\text { Prevalence of global } \\
\text { malnutrition } \\
\text { (<-2 z-score and/or } \\
\text { oedema) }\end{array}$ & $\begin{array}{c}(52) 5.6 \% \\
(4.2-7.495 \% \text { C.I.) }\end{array}$ & $\begin{array}{c}(32) 7.7 \% \\
(5.4-11.095 \% \text { C.I.) }\end{array}$ & $\begin{array}{c}(20) 3.9 \% \\
(2.7-5.695 \% \text { C.I.) }\end{array}$ \\
\hline $\begin{array}{l}\text { Prevalence of moderate } \\
\text { malnutrition } \\
(<-2 \text { z-score and >=-3 } \\
\text { z-score, no oedema) }\end{array}$ & $\begin{array}{c}(42) 4.5 \% \\
(3.3-6.395 \% \text { C.I.) }\end{array}$ & $\begin{array}{c}(26) 6.3 \% \\
(4.2-9.295 \% \text { C.I.) }\end{array}$ & $\begin{array}{c}(16) 3.1 \% \\
(2.2-4.595 \% \text { C.I. })\end{array}$ \\
\hline $\begin{array}{l}\text { Prevalence of severe } \\
\text { malnutrition } \\
\text { (<-3 z-score and/or } \\
\text { oedema) }\end{array}$ & $\begin{array}{c}(10) 1.1 \% \\
(0.5-2.395 \% \text { C.I. })\end{array}$ & $\begin{array}{c}\text { (6) } 1.5 \% \\
\text { (0.4-5.7 95\% C.I.) }\end{array}$ & $\begin{array}{c}\text { (4) } 0.8 \% \\
\text { (0.4-1.6 95\% C.I.) }\end{array}$ \\
\hline
\end{tabular}

Table 3. Prevalence of acute malnutrition by age based on $\mathrm{W} / \mathrm{H} z$-scores and/or oedema.

\begin{tabular}{|c|c|c|c|c|c|c|c|c|c|}
\hline \multicolumn{2}{|c|}{ Variables } & \multicolumn{2}{|c|}{$\begin{array}{c}\text { Severe } \\
\text { wasting } \\
(<-3 \text { z-score })\end{array}$} & \multicolumn{2}{|c|}{$\begin{array}{c}\text { Moderate } \\
\text { wasting } \\
(\geq-3 \text { and }<-2 \\
\text { z-score })\end{array}$} & \multicolumn{2}{|c|}{$\begin{array}{c}\text { Normal } \\
(\geq-2 \text { z score })\end{array}$} & \multicolumn{2}{|c|}{ Oedema } \\
\hline Age (mo) & Total no. & No. & $\%$ & No. & $\%$ & No. & $\%$ & No. & $\%$ \\
\hline Jun-17 & 249 & 3 & 1.2 & 22 & 8.8 & 224 & 90 & 0 & 0 \\
\hline $18-29$ & 194 & 1 & 0.5 & 11 & 5.7 & 177 & 91.2 & 5 & 2.6 \\
\hline $30-41$ & 215 & 0 & 0 & 2 & 0.9 & 212 & 98.6 & 1 & 0.5 \\
\hline $42-53$ & 202 & 0 & 0 & 6 & 3 & 196 & 97 & 0 & 0 \\
\hline $54-59$ & 62 & 0 & 0 & 1 & 1.6 & 61 & 98.4 & 0 & 0 \\
\hline Total & 922 & 4 & 0.4 & 42 & 4.6 & 870 & 94.4 & 6 & 0.7 \\
\hline
\end{tabular}

Table 4. Distribution of acute malnutrition and oedema based on $\mathrm{W} / \mathrm{H}$ $z$-scores.

\begin{tabular}{|c|c|c|}
\hline Variables & $<-3$ z-score & $\geq$-3 z-score \\
\hline \multirow{3}{*}{ Oedema present } & Marasmic kwashiorkor & Kwashiorkor \\
\cline { 2 - 3 } & No. 0 & No. 6 \\
\hline \multirow{3}{*}{ Oedema absent } & $0.00 \%$ & $-0.60 \%$ \\
\cline { 2 - 3 } & Marasmic & Normal \\
\cline { 2 - 3 } & No. 30 & No. 937 \\
\hline & $-3.10 \%$ & $-96.30 \%$ \\
\hline
\end{tabular}

malnutrition (GAM)- weight-for- height z-scores less than -2 SD and/or with bilateral oedema, severe acute malnutrition (SAM)-weight-for-height z-scores less than -3 SD and/or with bilateral oedema were used. Z-scores obtained from ENA were then incorporated into the Microsoft excel data. The data was then exported to Stata version 12 (Stata Corp., Texas). Continuous variables were compared using the student's t-test and categorical variables using the Chi-square test. Statistical tests were two-sided.

\section{Results}

A total of 1224 children ages 6-59 month were screened. For assessment of acute malnutrition, data for 978 children was considered clean for analysis. There were 440 (45.0\%) boys and $538(55.0 \%)$ girls, yielding a male: female ratio of 0.8 . The ratio of refugees to nationals was 1:3. Profiling the sample population by age, $27.5 \%$ were aged $6-17$ months, $21.4 \% 18$ 29 months, 23.2\% 30-41 months, 21.3\% $42-53$ months and $6.6 \%$ being in the age 54-59 months (Table 2). More than half $(61.7 \%)$ of the children were reportedly ill in the preceding twoweeks of the survey. The prevalence of the top three disease symptoms reported was: fever $(44.9 \%)$, cough $(13.3 \%)$, and diarrhea $(10 \%)$. Measles vaccination coverage (with card or confirmation from the mother) was $92.6 \%$ (91.1- $94.095 \%$ C.I.) among the children. Similarly, vitamin A supplementation in the preceding 6 months of the survey was reported among $95.4 \%$ of the children.

The overall prevalence of global acute malnutrition $(\mathrm{W} / \mathrm{H}$ $<-2$ z-score and/or oedema) was 5.6\% (4.2-7.4 95\% C.I.), moderate acute malnutrition $(\mathrm{W} / \mathrm{H}<-2 \mathrm{z}$-score and $\geq-3 \mathrm{z}$-score, no oedema) was 4.5\% (3.3-6.3 95\% C.I.) and severe acute malnutrition (<-3 z-score and/or oedema) was $1.1 \%(3.2-5.8$ $95 \%$ C.I.). Generally, the prevalence of all forms of acute malnutrition was higher among boys than in girls $(7.7 \%$ vs. $3.9 \%$ ). There were no statistically significant differences in prevalence of acute malnutrition by nationality (Nationals: $8.7 \%$ vs. Refugees: $6.2 \%, p=0.186$ ) implying that the problem was uniform across all the population pyramids in the survey area. The prevalence of low birth weight was 9.0\% (7.3-10.7, 95\% C.I.) and low birth weight (birth weight $<2.5 \mathrm{~kg}$ : $19.9 \% \mathrm{vs}$. birth weight $\geq 2.5 \mathrm{~kg}: 7.8 \%$ ) was associated with acute malnutrition $(\mathrm{p}=0.021)$. Severe acute malnutrition was more common among the younger age group 6-17 months $(1.2 \%)$ and decreased with age. The prevalence of oedema was $0.6 \%$ (Table 5 ).

\section{Discussion}

To the best of our knowledge, this is the first report of the state of nutrition among refugees and neighboring host communities in North-Western Uganda. Prevalence of global acute malnutrition among children 6-59 months in this survey was $5.6 \%$ and $1.1 \%$ of the children had severe acute malnutrition. By WHO thresholds for acute malnutrition, the level of GAM in this survey is described as poor and hence the need for nutrition interventions in the area. Compared to similar studies, the prevalence of acute malnutrition reported here is lower than the national average for this region [2] but consistent with our previous finding among under -5 s [14], a study conducted in an urban setting in Northwestern Uganda. The reasons for this difference may include study settings and the period in which the surveys were conducted. The National Demographic Survey was conducted over a six-month period starting about midJune to December 2016. This period captured data both in preharvest and harvest seasons of Northwestern Uganda. Whereas, the current survey was conducted during the first harvest season (August) for this region and hence the lower prevalence (than the national result for this region) of acute malnutrition reported here is not surprising. More so, the refugees in this setting have since been integrated into the local communities and are not extremely dependent on humanitarian assistance. Consistent with the report of Kelati et al. [15], the prevalence of acute malnutrition was higher in the younger age group (6-17 months) and boys compared to their female counterparts and children 
Citation: Legason ID, Dricile R. Prevalence of acute malnutrition among children ages 6-59 months: Results from a baseline nutrition survey in North-Western Uganda. J Nutr Hum Health. 2018;2(1):7-12

Table 5. Comparing the results with WHO thresholds for acute malnutrition.

\begin{tabular}{|c|c|c|c|c|}
\hline Index & & Indicator & Results & Who thresholds \\
\hline \multirow{2}{*}{$\begin{array}{l}\text { WHO Standard (2006) } \\
\qquad n=928\end{array}$} & \multirow{2}{*}{ Z- score } & $\begin{array}{c}\text { Global Acute } \\
\text { Malnutrition } W / \mathrm{H}<-2 \mathrm{z} \text { and/or oedema }\end{array}$ & $\begin{array}{c}(52) 5.6 \% \\
(4.2-7.495 \% \text { C.I.) }\end{array}$ & $\begin{array}{c}\text { WHO GAM } \\
\text { Emergency level } 15 \%\end{array}$ \\
\hline & & $\begin{array}{l}\text { Severe Acute Malnutrition } \\
\text { W/H }<-3 \text { z and/or oedema }\end{array}$ & $\begin{array}{c}(10) 1.1 \% \\
(0.5-2.395 \% \text { C.I. })\end{array}$ & $\begin{array}{c}\text { WHO SAM } \\
\text { Threshold } 2.00 \%\end{array}$ \\
\hline
\end{tabular}

18-59 months. The higher prevalence of acute malnutrition among the younger children (6-17 months) may be attributed to poor weaning and complementary feeding practices, which contribute to inadequate energy and protein intake [16]. The higher prevalence of acute malnutrition among boys may be related to the higher growth rate in boys resulting in greater need for nutrients not supplied by diet [17]. In one study it was suggested that boys are more affected by environmental stress than girls [17], if so boys may be more likely to suffer from malnutrition especially in societies where girls stay closely to their biological parents than boys who tend to go and stay with other relatives. We did not find statistical differences in the prevalence of acute malnutrition by nationality (nationals: $8.7 \%$ vs refugees: $6.2 \%, \mathrm{p}=0.186$ ) implying that the problem was uniform across all the population pyramids in the survey area.

In this study, having a low birth weight was statistically associated with acute malnutrition $(p=0.021)$, implying an early exposure to nutritional stress and therefore the need for nutritional intervention right from the time of child conception. The observed association between birth weight and acute malnutrition in children is consistent with findings of several other studies [18-22]. In one study, it was shown that children with low birth weight had 1.7 times (95\% CI: 1.53-1.92) risk of becoming wasted compared to those with normal birth weight [18]. The main cause of low birth weight especially in developing countries is intra-uterine growth retardation [23,24]. It is presumed that babies who suffer from intra-uterine growth retardation will be born malnourished. Studies have shown that about half of the cases of intra-uterine growth retardation in developing countries are due to maternal malnutrition at conception, and low weight gain during pregnancy [23,24]. Other reported causes of intra-uterine growth retardation include iron deficiency and anemia [25,26]. Studies have also shown that babies born to teenage mothers (age $<20$ years) are more likely to suffer from intra-uterine growth retardation and hence low birth weights [27,28]. A possible explanation is that the nutritional demand in a young mother is double as she struggles to complete her own growth. This therefore means that it is advisable for young married girls not to get pregnant until their bodies are mature and have completed their own growth. Special programs to create awareness among adolescent girls and married young women are therefore encouraged.

More than half of the children were reportedly ill in the preceding two-weeks of the survey and nearly half had fever, a figure higher than $42.1 \%$ reported in the National Demographic Survey [2]. This proportion of child morbidity is higher than normal and should receive further investigation and attention. Malnutrition and child morbidity have a synergistic relationship. Malnutrition can impair the immune system hence leading to increased susceptibility to infectious diseases [29]. On the other hand, helminthic infections, malaria and diarrhea have direct impact on malnutrition [29,30]. For instance, hookworm infections lead to loss of blood and nutrients as a result of the blood sucking activities of the worms [30]. Illnesses can also lead to malnutrition by suppressing appetite of an individual for food hence malnutrition [29]. Measles vaccination rates were $92.6 \%$ well above the national average of $82.0 \%$ [2] and more than ninety percent of the children had received Vitamin A supplementation in the preceding 6 months of the survey. The higher measles vaccination rates observed in this survey may be attributed to the increased humanitarian assistance for EPI targeting refugee populations in the region.

Some of the limitations of the current study include; technical errors in determining anthropometric measurements which could have led to misclassification of children's nutritional status, self-reported indicators such as child morbidity may be subject to recall bias, and the period in which the survey was conducted may have greatly influenced our nutritional results.

\section{Conclusion}

Compared to WHO thresholds, our results indicate that the occurrence of global acute malnutrition is a moderate problem in the refugee areas of Koboko district and that GAM is not only a problem of refugees but also the host communities. Our finding that more than half of the children were ill in the preceding 2 weeks of the survey suggests for an ICCM program for better child health indicators. The survey was conducted in August, a period of harvest which might have influenced the prevalence of acute malnutrition. Another survey is recommended during the hunger gap period to give a year-round nutrition situation in Koboko.

\section{Declarations}

\section{Ethics approval and consent to participate}

The offices of the District Health Officer and Prime Minister were informed accordingly. The assessment was part of a program implemented by AFOD, a project funded by World Food Program. Informed consent was obtained from each participant prior to the screening. Participants were further assured of anonymity, confidentiality and privacy in the survey.

\section{Funding}

This work was funded by Alliance Forum for Development Uganda prior to implementation of the MCHN and TSFP project in refugee settlement areas in Koboko district. The project is funded by World Food Program and implemented by Alliance Forum for Development Uganda with technical support from Health and Development for All (HADA) Uganda.

\section{Acknowledgements}

We are grateful to the donor (World Food Program) and the implementing partner (Alliance Forum for Development) for the financial support received for conducting the survey. We thank the Ministry of Health, Office of the Prime Minister and 
District Health Office of Koboko for supporting this work. The support from all our partners including the Health facilities in the survey area is also acknowledged. We thank our community mobilizers and the data collectors for the job well done. We are grateful to the children and their parents or care takers for participating in the survey. Lastly, we thank the leadership of AFOD, in particular, Mr. Sunday Mawa and Mr. Tabo Fred for coordinating field logistics.

\section{References}

1. United Nations Children's Fund, World Health Organization, and the World Bank. UNICEFWHO- World Bank Joint Child Malnutrition Estimates. (UNICEF, New York; WHO, Geneva; The World Bank, Washington, DC; 2012).

2. Uganda Bureau of Statistics (UBOS) and ICF. Uganda Demographic and Health Survey 2016: Key Indicators Report. Kampala, Uganda: UBOS, and Rockville, Maryland, USA. 2017.

3. UNICEF Joint press release: South Sudan famine ebbs, but situation still desperate as hunger spreads. ROME/JUBA, South Sudan, 21 June 2017.

4. Victoria CG, Adair L, Fall C, et al. Maternal and child under nutrition study group. Maternal and child under nutrition: Consequences for adult health and human capital. The Lancet. 2008;371:340-357.

5. Nyaradi A, Li J, Hickling S, et al. The role of nutrition in children's neurocognitive development, from pregnancy through childhood. Frontiers Human Neurosci.2013;7:97.

6. Morgan, Kristiana E. The cognitive effects of chronic malnutrition and environment on working memory and executive function in children. Independent Study Project (ISP) Collection. 2015;2053.

7. European Commission. Enhancing Maternal and Child Nutrition in External Assistance: An EU Policy Framework. Communication from the Commission to the European Parliament and the Council, Brussels COM. 141 Final. 2013.

8. UN High Commissioner for Refugees (UNHCR), Uganda: Emergency Update on the South Sudan Refugee Situation Inter-Agency Weekly $\mid 22^{\text {nd }}-28^{\text {th }}$ February 2017.

9. UN High Commissioner for Refugees (UNHCR), South Sudan's refugee crisis now world's fastest growing, Uganda and region in critical need of help, 17 March 2017.

10. UN High Commissioner for Refugees (UNHCR), More than 6,000 flee fresh South Sudan violence into Uganda, 7 April 2017.

11. UN High Commissioner for Refugees (UNHCR), UNHCR assures Uganda of international commitment to support its refugee protection, management and social integration policies, 13 April 2017.

12. Uganda Bureau of Statistics. The National Population and Housing Census 2014- Main Report, Kampala, Uganda.2016.

\section{3. https://biobank.ctsu.ox.ac.uk/crystal/docs/Height.pdf}

14. Legason ID, Atiku A, Ssenyonga R, et al. Prevalence of anaemia and associated risk factors among Children in North-western Uganda: A cross sectional study. BMC Haematology. 2017; 17: 10.

15. Kelati H, Mengiste B, Alemayehu T, et al. Prevalence of acute malnutrition and its associated factors among children aged 6-59 months in Mai-Aini Eritrean Refugees' Camp, Northern Ethiopia. J Nutr Food Sci. 2015;5:336.

16. Mittal A, Singh J, Ahluwalia SK. Effect of maternal factors on nutritional status of 1-5-year-old children in urban slum population. Indian J Community Med. 2007;32:264-267.

17. Wells JC. Natural selection and sex differences in morbidity and mortality in early life. J Theor Biol. 2000;202:65-76.

18. Rahman MS, Howlader T, Masud MS, et al. Association of low-birth weight with malnutrition in children under five years in Bangladesh: Do mother's education, socioeconomic status, and birth interval matter? PLoS ONE. 2016;11:e0157814.

19. Islam MM, Alam M, Tariquzaman M, et al. Predictors of the number of under-five malnourished children in Bangladesh: application of the generalized poisson regression model. BMC Public Health. 2013;13.

20. Mishra K, Kumar P, Basu S, et al. Risk factors for severe acute malnutrition in children below 5 y of age in India: A case-control study. Indian J Pediatr. 2014;81:762-765.

21. Wong HJ, Moy FM, Nair S. Risk factors of malnutrition among preschool children in Terengganu, Malaysia: A case control study. BMC Public Health. 2014;14:1-10.

22. Haque SMR, Tisha S, Huq N. Poor birth size a badge of low birth weight accompanying less antenatal care in Bangladesh with substantial divisional variation: Evidence from BDHS-2011. Public Health Research. 2015;5:184-91.

23. Arifeen SE, Black RE, Caulfield LE, et al. Infant growth patterns in the slums of Dhaka in relation to birth weight, intrauterine growth retardation, and prematurity. Am J Clin Nutr. 2000;72:1010-17.

24. Kramer M. Determination of low birth weight: Methodological assessment and meta-analysis. Bull World Health Org. 1987;65:663-737.

25. Rasmussen K. Is there a causal relationship between iron deficiency or iron-deficiency anemia and weight at birth, length of gestation and perinatal mortality? J Nutrition. 2001;131:601-03.

26. Allen LH. Anaemia and iron deficiency: Effects on pregnancy outcome. Ame J Clin Nutrition. 2000;71:1280-84.

27. Dhar B, Mowlah G, Nahar S, et al. Birth weight status of newborns and its relationship with other anthropometric parameters in a public maternity hospital in Dhaka, Bangladesh. J Health Popul Nutr. 2002;20:36-41.

28. Tin TT, Thida M, Maung MM, et al. Maternal influences on low birth weight. Malays. J Repro Health. 1994;12:32-7. 
Citation: Legason ID, Dricile R. Prevalence of acute malnutrition among children ages 6-59 months: Results from a baseline nutrition survey in North-Western Uganda. J Nutr Hum Health. 2018;2(1):7-12

29. Pelletier DL, Frongillo EA Jr, Schroeder DG, et al. The effects of malnutrition on child mortality in developing countries. Bull World Health Organ. 1995;73:443-48.
30. Hotez PJ. Pediatric geohelminth infections: Trichuriasis, ascariasis, and hookworm infections. In: Seminars in paediatric infectious diseases. 2000;11:236-44.

\section{*Correspondence to:}

Ismail D. Legason

African Field Epidemiology Network

Kampala

Uganda

Tel: +256774243773

E-mail: legason15@gmail.com 